\title{
Current Trends In Research, Development And Production Of Prophylactic Vaccines: Report of Vaccipharma 2015 Congress
}

\author{
Acevedo $\mathbf{R}^{1 *}$, Landys $\mathbf{M}^{1}$, García-Rivera $D^{1}$, Fernandez $S^{1}$, Alvarez $\mathbf{N}^{1}$, Ferro VA ${ }^{2}$, Pagliusi $S^{3}$, \\ Holst J ${ }^{4}$ \\ ${ }^{1}$ Finlay Vaccine Institute, Cuba \\ ${ }^{2}$ University of Strathclyde, Strathclyde, Institute of Pharmacy and Biomedical Sciences (SIPBS), Glasgow, Scotland, UK \\ ${ }^{3}$ Executive Secretary DCVMN International, Switzerland \\ ${ }^{4}$ Division of Infectious Disease Control, Norwegian Institute of Public Health, Oslo, Norway.
}

Received: August 23, 2016; Accepted: September 2, 2016; Published: October 25, 2016

*Corresponding author: Acevedo R, Finlay Vaccine Institute,Cuba.E-mail: racevedo@finlay.edu.cu

\begin{abstract}
On June 14-19, 2015, the IUPHAR Section of Immunopharmacology and the Cuban Society of Pharmacology, together with the LatinAmerican Association of Pharmacology (ALF), Finlay Vaccine Institute and other prestigious Cuban scientific institutions, organized the Congress VACCIPHARMA 2015 (3rd International Congress on Pharmacology of Vaccines), held as part of the First International Convention IMMUNOPHARMACOLOGY-VACCIPHARMA 2015 (Meliá Marina Varadero Hotel, in Varadero beach, Cuba)

VACCIPHARMA 2015 was organised into two large Workshops, addressing topics related to the research, development, clinical evaluation, production and quality control of Therapeutic and Prophylactic Vaccines, respectively. At the same time the Workshop on Prophylactic Vaccines was integrated by several Symposiums, focused on meningococcal, pneumococcal, enteric, tuberculosis and pertussis vaccines. About 250 delegates, including 100 international researchers from 15 countries, attended this meeting.
\end{abstract}

The Congress had a remarkable Opening Session, with a Key Lecture given by the outstanding scientist Professor Dr. Shiv Pillai (United States of America), who talked about the changing views in the field of the immunology of vaccination and the challenges ahead.

The aim of this review is to give an overview of the main topics discussed in the Prophylactic Vaccines Workshop, not as a complete narration of the events, but to provide an update of the latest state of the art and methodologies being applied to prophylactic vaccines with an expert commentary on the invited speakers.

Keywords: Vaccine; Neissseria meningitidi; Mycobacterium tuberculosis; Combined vaccines; Enteric Vaccines; Pneumococcal Vaccines; Bordetella pertussis; Salmonella Typhi;

\section{Combined Vaccines. The Pertussis problem}

The Symposium in Combined Vaccines was focused on research and development of pertussis vaccines as one of the most important components of combined vaccines. Also known as whooping cough, this has been one of the most persistent and extended infectious diseases, with more than 200000 deaths per year and 20 million cases worldwide, according to the World Health Organization (WHO). This situation exists today in spite of high vaccine coverage [1]. A first generation of vaccines consisting of suspensions of Bordetella pertussis cells has been used since the 1940s with high levels of efficacy. However, concerns about several drawbacks such as local reactions, fever and even some not substantiated neurological disorders has driven the development and application of vaccines based on isolated and purified antigens as opposed to whole cells. This second generation of acellular vaccines (aP) containing either three or five purified antigens adsorbed to alum and co-formulated with other antigens, although less reactogenic, has not conferred the same level of protective immunity against B. pertussis as the original whole-cell pertussis ( $\mathrm{wP}$ ) vaccines [2]. In fact, its introduction in the 1980s has been linked to the resurgence of whooping cough in developed countries, where had changed from $w \mathrm{P}$ to aP vaccines. One explanation of the failure of these aP vaccines is attributed to the induction of IgG1 antibodies and $T$ helper-2 (Th-2) cells, whereas the wP vaccines generate a Th-1/ Th-17 response, which is thought to be important for protection against $B$. pertussis. One solution to the ongoing problem might be a return to $\mathrm{wP}$, but this is generally viewed as unfeasible in countries where aP vaccines are established. Therefore, a third generation of vaccines and new strategies regarding vaccination schedules and policies are in progress [3].

In this context, the session on pertussis vaccines started with a presentation from Dr. Waldely O. Dias (Butantan Institute, Brazil), who described the development of an improved wP vaccine, designated as Plow, with low endotoxicity, using a simplified and not expensive methodology, which also produced monophosphoryl lipid A as a by-product, to be used as an adjuvant. This new wP vaccine with low lipo-oligosaccharide (LOS) content, due to a chemical extraction of LOS from the outer membrane, when combined with diphtheria and tetanus antigens 
(DTPlow) was shown to be as potent as the current pertussis whole cell combined vaccine (DTP vaccine) but less reactogenic. The LOS extraction did not affect the integrity of the product and, more importantly, did not impact on the potency, immunogenicity and/or stability of DTPlow. Thus, this new approach for $\mathrm{wP}$ vaccines could be a significant improvement and a promising and affordable alternative to currently available pertussis vaccines for developing countries [4].

Dr. Arno van der Ark (Netherlands Institute for Translational Vaccinology, Intravacc, the Netherlands) discussed the value of product characterization and immunoproteomic profiling in the search of improved pertussis vaccines, based mainly on outer membrane vesicles (OMV) [5]. In his presentation, Dr. van der Ark showed the results of the comparative characterization of $\mathrm{wP}$ and OMV vaccines using microarrays for gene expression and enzyme linked immunoassays (ELISA) to evaluate antigen content, as well as immunoprofiling by liquid chromatography mass spectroscopy (LC-MS) and 2 dimensional (2-D) electrophoresis/blotting as well as immunogenicity in mice. Both types of vaccine raised strong antibody responses, but large quantitative and qualitative differences were measured. The highest antibody levels were obtained by OMV. The wP vaccine induced IgG2a/IgG2b/IgG3 levels which were significantly lower compared to OMV. The majority of OMV-induced antibodies were directed against Vag8, BrkA and lipopolysaccharide (LPS) whereas wP-induced antibodies were mainly directed against GroEL, FHA and Vag8. The higher IgG2a, IgG2b and IgG3 antibody responses induced by OMV indicate more functional antibodies were induced, although this needs to be confirmed in functional assays [6].

A presentation by Dr. Diógenes Quintana (Center of Genetic Engineering and Biotechnology, CIGB, Cuba) introduced his work on the design of new recombinant molecules comprising the complete sequences/regions of two different types of pertactin (PRN). PRN molecules bear two variable R1 regions from Prn1 and Prn2. The genes of Prn1, Prn2 and six variants of PRN were cloned in Escherichia coli, and PRN proteins were over-expressed at $25-30 \%$ of total protein concentrations using the pET28a/BL21 Codonplus RP expression system. The proteins were purified and after refolding, the PRNs were recognized by anti-PRN monoclonal antibodies binding protective conformational and linear epitopes/ regions. The PRN proteins were highly immunogenic in BALB/c mice, with the induction of IgG2a and IgG2b subtypes. In particular, two PRNs (PRN2-lc-1 > PRN2-1) induced highly significant ( $p$ $<0.001$ ) anti-Prn1 antibody levels. The PRN2-lc-1 and PRN2-1 molecules exhibited an enhanced immunological profile in BALB/c mice in terms of the level of whole anti-Prn IgG antibodies with respect to natural Prn controls.

Dr. Coenraad Hendriksen (Intravacc, the Netherlands) outlined the consistency approach, the new paradigm in lot release testing of established vaccines. This approach starts from the idea that subsequent lots of vaccine produced can be compared with a clinical/historical lot, which is thoroughly tested and has a well defined profile [7]. The consistency approach has come into being by improvements in production and control: optimized production processes, a tight protocol for in-process testing (using innovative physico- and immunochemical techniques, in vitro cell culture techniques and bioinformatics) and a state-of-the-art quality monitoring system (Good Manufacture Practice GMP, Quality Assurance QA). Consistency testing may lead to a significant reduction in animal use, since a narrow set of animal tests performed on each final lot, sometimes with questionable relevance, may be replaced by a battery of meaningful physicochemical-, immunochemical- and in vitro functional tests with enhanced capacity to measure equivalence with batches of proven safety and efficacy. Dr. Hendriksen also showed some proof of concept data of the consistency testing for pertussis, rabies and diphtheria vaccines [8].

Finally, Dr. Mario Landys Chovel (Finlay Vaccine Institute, Cuba) discussed the development of a pertussis serological potency test (PSPT) and its correlation with protection. The Mouse Protection Test (MPT) still remains the "gold standard" for Pertussis Potency in vaccines, but it has been broadly criticized in terms of variability, scientific relevance, ethics and high cost. As PSPT correlates well with MPT, it appears to be a very promising alternative to the challenge method. However, its biological relevance, namely the mechanisms related to the role of the antibodies detected with protection, are rather unclear. Dr. Chovel showed that whole antibody titres, instead of specific antibody titres, correlated with MPT activities. Likewise, IgG2a and IgG2b subclasses were generated during the PSPT, suggesting a role for antibodies in inducing phagocytosis by phagocytes like neutrophils and macrophages. The results derived from an in vitro opsonophagocytosis model correlated well with the PSPT and the MPT, confirming this pathway as significant in explaining the role of the antibodies in the protection induced by wP. Thus, this alternative method could provide not only a potential replacement of MPT, but also a valuable tool for estimating the biological relevance of new pertussis vaccines [9].

\section{Pneumoccocal Vaccines. Learned Lessons}

The main goals of the Pneumococcal Vaccine Symposium, were to provide an update on scientific information about Pneumococcal Conjugate Vaccines (PCV) and to share with international experts the strategy for the development of the Cuban pneumococcal conjugate vaccine.

The chairmen of the Symposium were two prestigious scientists: Dr. David Goldblatt, Director at the WHO Pneumococcal Reference Laboratory, Institute of Child Health, University College London, UK, and Dr. Vicente Verez-Bencomo, General Director of Finlay Vaccine Institute, Havana, Cuba. Other important speakers were Dr. Ron Dagan from the Faculty of Health Sciences, Ben-Gurion University of the Negev, BeerSheva, Israel., Prof. Katherine O'Brien from Johns Hopkins Bloomberg School of Public Health, USA. Dr. Maria Catalina Pirez from Facultad de Medicina, Universidad de la República, Uruguay. Dr Gail Rodgers, from Bill and Melinda Gates foundation, USA. The first session of the symposium focused on pneumococcal diseases around the globe, the impact of PCV on pneumococcal diseases and carriage, and the lessons learned after 15 years after PCV7 was launched. The second session of 
the symposium was dedicated to update and critically review the development of a new PCV in Cuba.

In 2000, about 14.5 million episodes of serious pneumococcal disease were estimated to occur. Pneumococcal disease caused about 826, 000 deaths in children aged under 5 years, of which $~ 91$, 000 were in HIV positive and $\sim 735,000$ in HIV negative children. Of the deaths in HIV negative children, over $61 \%$ occurred in ten African and Asian countries [10]. Three pneumococcal conjugate vaccines are licensed against $S$. pneumoniae serotypes: Prevnar7 or PCV7 (Pfizer, USA) against serotypes 4, 6B, 9V, 14, 18C, 19F and 23F; Synflorix or PCV10 (GlaxoSmithKline, Belgium) includes antigens for serotypes 1, 4, 5, 6B, 7F, 9V, 14, 18C, 19F and 23F; and Prevnar13 or PCV13 (Pfizer, USA) contains antigens for serotypes $1,3,4,5,6 \mathrm{~A}, 6 \mathrm{~B}, 7 \mathrm{~F}, 9 \mathrm{~V}, 14,18 \mathrm{C}, 19 \mathrm{~A}, 19 \mathrm{~F}$ and $23 \mathrm{~F}$.

The introduction of Prevnar-7 in the USA in 2000 was an important success in the fight against pneumococcal diseases, due to its high efficacy in preventing diseases and death caused by pneumococci. Also, a reduction of child mortality was reported in children below 2 years and a substantial decrease in Invasive Pneumococcal Disease (IPD) in other non-immunized age groups was documented $[11,12]$. For many years in the last decade, the vaccine was only available for developed countries. Nowadays, the licensed PCV Prevnar-13 and Synflorix are available in many countries of the world, even in very poor countries thanks to the efforts of GAVI, with more than 50 countries now having rolled out the vaccine [13]. On the other hand, several middle income countries are non-eligible for GAVI, therefore they are not able to access them because of the high price of these vaccines.

WHO recommends the inclusion of pneumococcal vaccines in childhood immunization programs worldwide, especially in countries with under-five mortality of greater than 50 per 1000 live births. Schedules of three primary doses $(3 p+0)$ or, as an alternative, two primary doses plus a booster $(2 p+1)$ are recommended, although the $3+1$ is still used in several developed countries. Primary vaccination can be initiated as early as at 6 weeks of age. WHO also recommends catch-up vaccination during pneumococcal vaccine introduction to accelerate herd protection and PCV impact on disease and carriage [14]. The differences between the $2 p+1$ and $3 p+0$ schedules are subtle, especially in countries with a mature immunization program in which coverage is high and indirect effects help enhance protection provided directly by a vaccine schedule [15].

Strong evidence was provided during the session about the efficacy and the impact of PCV established through multiple clinical trials. PCV7 demonstrated efficacy of $97.4 \%$ against invasive pneumococcal disease caused by serotypes contained in the vaccine [11]. PCV10 has been effective against invasive pneumococcal diseases in Brazil, with 83.8\% (95\% CI 65.9-92.3) against vaccine serotypes, and $77 \cdot 9 \%(41 \cdot 0-91 \cdot 7)$ against vaccinerelated serotypes [16]. PCV13 has recorded data on efficacy, initially inferred before licensure from an aggregate correlate of protection, established for PCV7; and later, a post-licensure assessment of serotype-specific vaccine effectiveness and immunogenicity in England, Wales, and Northern Ireland was reported, with vaccine effectiveness of $90 \%$ (34-98) for the PCV7 serotypes and 73\% (55-84) for the six additional serotypes included in PCV13 [17]. Other non-licensed vaccines were also effective preventing pneumonia and mortality in different regions $[18,19]$.

The need of alternative PCV dosing schedules was also discussed during the symposium, based on the need for some countries to reduce cost of their immunization programs. Thanks to the work of GAVI and Vaccine Alliance partners, most of the world's poorest children are now receiving PCV, but the sustainability of this vaccination could be compromised when these countries graduate from GAVI and one of the strategies is the reduction of the number of PCV doses. Rückinger et al. [20] have published a metanalysis estimating that about $10 \%$ fewer children achieve antibody levels of $\geq 0.35 \mu \mathrm{g} / \mathrm{ml}$ after two primary immunizations compared to three primary immunizations for most of serotypes included in one of the licensed pneumococcal conjugate vaccines. This difference in proportion was higher for serotypes $6 \mathrm{~B}$ and $23 \mathrm{~F}$, where $-49.4 \%(-66.0 ;-32.9 \%)$ and $-26.9 \%(-37.2 \% ;-16.6 \%)$ fewer children achieved protective antibody levels. These findings support the fact that the majority of children were protected by two primary immunizations with pneumococcal conjugate vaccines in the first year of life [21]. Then, following the control of pneumococcal vaccine-type disease and colonization through vaccination could be decided by some countries by changing the PCV schedule to single priming and a booster dose would be sufficient to sustain that control at reduced costs [22]. This option should be evaluated and clinical evidence should be generated for supporting this approach.

Professor David Goldblatt provided an update on the next generation of pneumococcal vaccines. Some PCV are under development by manufactures, such as Merck (a 15-valent vaccine), Serum Staten Institute of India (a 10-valent vaccine), Finlay Vaccine Institute, Cuba (a 7-valent vaccine), among some others. It may be difficult for manufacturers not belonging to the big pharmaceutical companies to enter the PCV market, but many countries will be graduating from GAVI eligibility over the next 5 years so there is a market for cheaper vaccines that can be supplied to these countries and which will cover the key serotypes prevalent in those countries. Undoubtedly, the effectiveness of PCVs has led to the development of higher valence vaccines, to combat in part, serotype replacement, but it is unclear how many serotypes can be added to a single conjugate vaccine and serious physico-chemical and immunological challenges are expected. Nevertheless, as the Target Product Profile has recognized, the combination of 7-8 of them could be enough to cover more than $60 \%$ of the invasive disease isolates in the target region and considerable public health impact may be expected [23].

Protein based vaccines offer the promise of serotypeindependent immunity, but not even one has been licensed until now, mainly because the regulatory pathway for their licensure remains undefined. New vaccines containing highly conserved Streptococcus pneumoniae proteins such as pneumolysin toxoid (dPly) and histidine-triad protein D (PhtD) are being developed 
to provide broader protection against pneumococcal disease, which are well tolerated and immunogenic when administered to healthy adults [24]. Several approaches have been followed for protein-based vaccines. One strategy has been the combination of proteins with conjugates. The combination of PCV10 Synflorix with PhtD and dPly were immunogenic either for polysaccharide and protein antigens, and the investigational vaccine formulations were well-tolerated when administered to toddlers as a 2-dose primary vaccination followed by a booster dose [25]. PCV13 has been evaluated in combination with two pneumococcal proteins in Navajo Indians, with 1800 subjects, 900 with PCV13 and 900 with PCV13 more PhtD and dPly proteins. This clinical trial has as primary endpoint clinical OAM, and the secondary endpoint is efficacy against nasopharyngeal carriage of non-PCV serotypes (Goldblatt personal communication). Another strategy has been to use pneumococcal proteins as a carrier for capsular polysaccharide. A clinical trial was conducted in healthy elderly adults to examine the safety, reactogenicity, and immunogenicity of six different investigational pneumococcal vaccine formulations containing AS02V or alum adjuvant with PhtD and dPly proteins either conjugated to pneumococcal polysaccharide in an 8-valent PCV (8PCV) or as free proteins [26]. Nevertheless, the regulatory pathway for the licensure of protein-based vaccines is unclear and correlates of protection need to be found.

The final session of the symposium was dedicated to the discussion and critical review of the Cuban strategy for the development of a heptavalent pneumococcal conjugate vaccine PCV7-TT (using tetanus toxoid, TT, as a carrier) and the implementation of a clinical research strategy and impact evaluation of this new vaccine. This candidate vaccine has been developed by the same research team that developed the first human vaccine using a fully synthetic polysaccharide antigen: Quimi-Hib [27]. The PCV7-TT vaccine was designed to be used in Cuba and other countries with the good ratio of cost-effectiveness. In contrast to the current PCV-10 and PCV-13 strategies, the number of serotypes was kept at seven, but with a more rational selection than the original PCV7; five serotypes: $6 \mathrm{~B}, 14,18 \mathrm{C}, 19 \mathrm{~F}$ and $23 \mathrm{~F}$ are the same compared to the original Prevnar-7 formulation, but serotypes 1 and 5 were additionally included, instead of increasing the number of serotypes, and the corresponding 4 and $9 \mathrm{~V}$ serotypes were not included because they are found in lower prevalence than 1 and 5 worldwide. Additionally, an important cross-protection is expected for serotypes 6A and 19A. The Cuban strategy keeps the number of serotypes at seven, as it is considered the best number to get wide coverage and to enable faster vaccine development. The candidate vaccine contains as active ingredients the CPS of serotypes 1, 5, 6B, 14, 18C, 19F and 23F, coupled by reductive amination to $\mathrm{TT}$, adsorbed on aluminum phosphate as the adjuvant. The preclinical research stages of this vaccine have demonstrated immunogenicity and safety in animal models, the technology has been scaled up and several batches have been produced for clinical trials.

The clinical research strategy and impact evaluation of this vaccine is based on the necessity to introduce pneumococcal vaccines into the Cuban National vaccination program to impact on the burden of IPD, and to provide scientific evidence to support the use and commercialization of this vaccine in the PCV13 era. The clinical evaluation strategy and impact evaluation for this vaccine is summarized in Figure 1.

The PCV7-TT vaccine was initially evaluated in 40 healthy young adults during a controlled, randomized and double blind Phase I clinical trial, using polysaccharide vaccine Pneumo-23 (Sanofi-Pasteur) as a control. This clinical trial demonstrated that the candidate vaccine PCV7-TT was safe when used in healthy adults and immunological results showed that after a single dose, the concentration of antibodies increased significantly in both groups with respect to pre-vaccination levels [28]. The clinical trial was published in the Cuban Public Register of Clinical Trials with code RPCEC00000133.

Once the safety in adults was demonstrated, a controlled, randomized (ratio 1:2) and double blind Phase I, clinical trial was designed to assess the safety and to explore the immunogenicity of PCV7-TT in 15 children, aged 4-5 years old. This clinical trial was designed as a bridge recommended by the Cuban National Regulatory Agency to assess the safety in children around 5 years old prior to authorizing clinical trials in infants; this was the reason for the small sample of children. The primary outcome of this study was safety, but immunogenicity was also explored. PCV7-TT was well tolerated and as safe as Synflorix used as the control vaccine. Following a single-dose vaccination, all individual serotypes included in the PCV7-TT vaccine induced a statistically significant increase of antibodies and opsonophagocytic activity (IgG GMC and OPA GMT), and the first evidence of a possible cross-protection against serotypes $6 \mathrm{~A}$ and 19A were observed [29]. These were the first clinical results for PCV7-TT in children and they paved the way towards the next clinical trials in children and infants. This clinical trial was published in the Cuban Public Register of Clinical Trials with code RPCEC00000173.

During 2014-2015, a parallel, controlled, randomized and double blind Phase II/III, clinical trial was initiated in Cienfuegos, Cuba, with the aim to demonstrate the immunogenicity and efficacy of PCV7-TT compared with Prevnar-13. Children, 1140, aged 1-5 years old, who had not received prior pneumococcal vaccination, were enrolled into the study. This trial finished in the first semester of 2017, and if the results are positive, it will allow the license of the vaccine for this population.

Clinical trials in children and infants was the next stage in clinical evaluation of this vaccine in order to obtain a license for these target populations. Firstly, we evaluated the vaccine in infants of 7 months old, with a schedule at 7, 8 and 11 months, and the results showed low reactogenicity (unpublished data). During 2016, a Phase I/II clinical trial have been doing in infants 2 month-old.

The PCV7-TT vaccine will be licensed in Cuba firstly for children and then for infants, with a window of a year or two. This time will give us the unique possibility to study the impact of PCV vaccination on infants and other unvaccinated populations [30,31]. The current PCVs were initially introduced in infants, sometimes accomplished by a catch-up for children; 


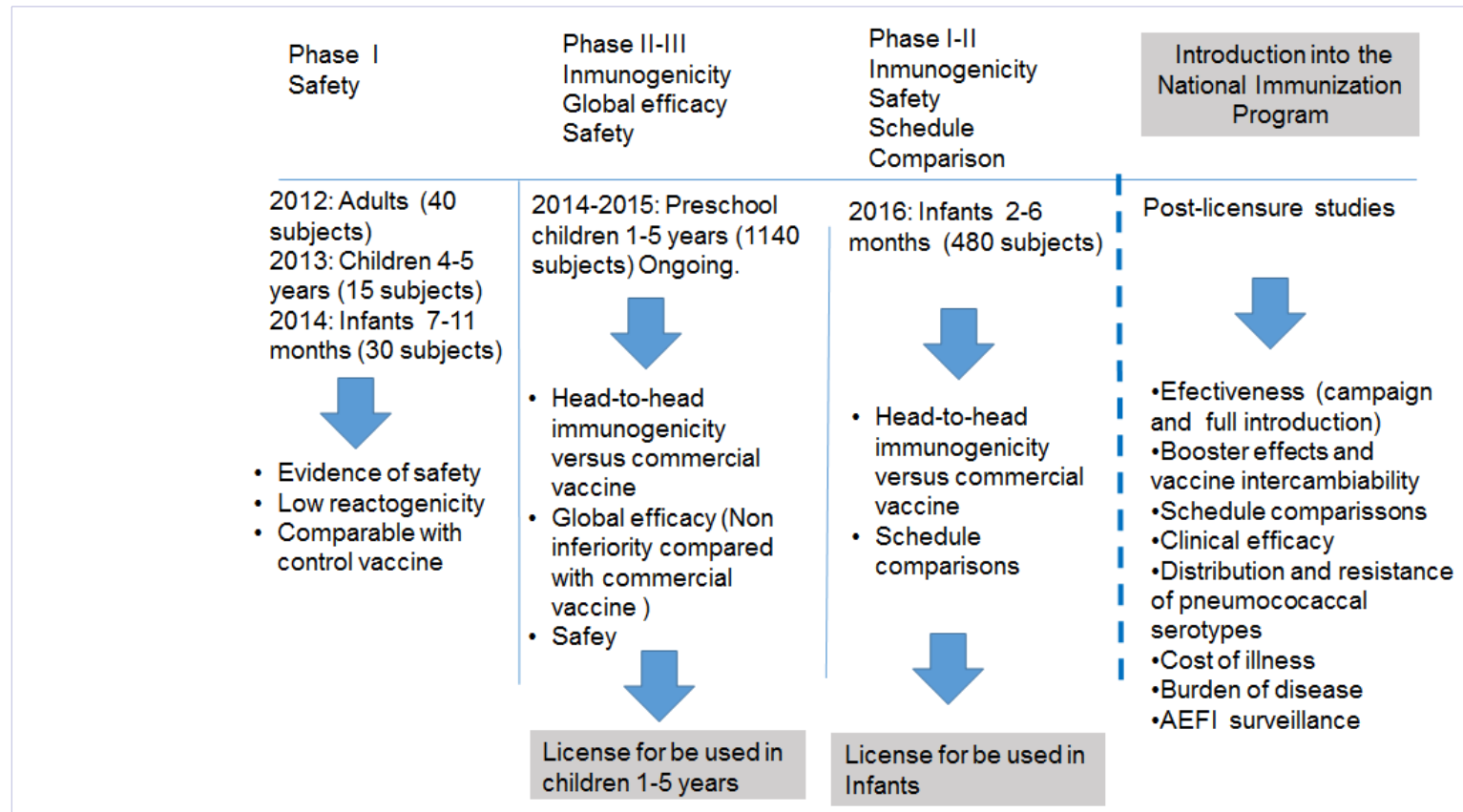

Figure 1: Summary of the clinical evaluation strategy for effectiveness and impact of Cuban PCV7-TT vaccine

but the Cuban experience could be, as far as we know, the first experience in the world where the indirect impact on infants could be evaluated by vaccinating with PCV in children.

The Cuban strategy will introduce vaccination of children between 1-5 years old as a short-term mass vaccination campaign with high coverage, contributing to provide scientific evidence about the impact on reduction of nosocomial pneumonia colonization rates and the incidence of IPD in vaccinated and unvaccinated subjects, including infants. Excellent results were found in a mass campaign with MenAfrivac in Mali, Burkina Faso and some other African countries based on similar strategy [30,31].

\section{Enteric Vaccines. The promise of the future}

The Enteric Vaccines (EV) Symposium received prominent experts and members of international programs involved in the development of vaccines against enteric pathogens.

Food/waterborne diseases are a worldwide problem and a major cause of childhood deaths in developing countries [32]. Certainly, the best strategy of control will be the improvement of water supplies and sanitation; however, these measures may not be achievable in the near future in most developing countries. For that reason, vaccination has become a short- to mid-term strategy [33].

\section{Salmonella Typhi and Paratyphi A}

Caused mainly by Salmonella enterica serovar Typhi and serovar Paratyphi A, enteric fever is still an important public health problem in many developing countries [34]. Even though live attenuated and Vi capsular polysaccharide vaccines have been available for more than 30 years ago, almost no country has implemented vaccination against typhoid at country level. Part of the reason for their lack of use in at-risk populations is their short-term protection and poor immunogenicity in young children [35]. At present no vaccines specific to $S$. Paratyphi A are available. In this regard, a new generation of improved vaccine candidates has been emerging; all focused on the induction of a long-lasting immune response in all age groups. Among them, anti-typhoid conjugate vaccines is the most advanced strategy, with three vaccines already licensed for incountry use in India and China [36]. Similarly, efforts have been made in the development of candidates against Paratyphi $\mathrm{A}$, in order to obtain a bivalent vaccine versus both pathogens [36].

Dr. Sushant Sahastrabuddhe, Program Leader of Enteric and Diarrheal Diseases at International Vaccine Institute (IVI, Korea), introduced the session with a presentation about the burden of typhoid and paratyphoid fever and the strategies for control. Dr. M. Imran Khan, former Director of Coalition against Typhoid discussed how even though vaccines against typhoid have been available for several years, the absence of global financing support has resulted in minimal national uptake. However, GAVI commitment to support a typhoid conjugate vaccine is encouraging. Dr. Khalid Ali Syed, Associate Research Scientist from IVI, talked about the typhoid conjugate vaccine candidate developed at IVI, its technology transfer to four manufacturers and the clinical development plan for use in children less than 2 years of age. He also discussed the need of a paratyphoid vaccine based on the significant disease burden, the increasing antimicrobial resistance and the non existence of vaccines against this disease. On the other hand, Sonsire Fernández, Project Manager at Finlay Vaccine Institute, showed the impact of sanitation measures and typhoid vaccination with 
a Vi polysaccharide vaccine (vax-Tyvi ${ }^{\circledR}$, Finaly Vaccine Institute) on the disease incidence in Cuba. In addition, she presented the Cuban project of development of a typhoid conjugate vaccine, which has achieved successful results at preclinical stage [37].

\section{ETEC-Shigella-Cholera}

Diarrhea remains a major cause of childhood morbidity and mortality worldwide [38]. Vibrio cholerae, Shigella spp. and Enterotoxigenic Escherichia coli (ETEC) are among the numerous pathogens (bacteria, parasites and viruses) that cause diarrheal infectious diseases in humans.

Together, ETEC and Shigella infections represent nearly onethird of annual diarrhea episodes in Africa and South Asia [39]. Additionally, ETEC is responsible for one-third to one-half of diarrhea in travelers returning from Asia, Latin America and Africa [40]. Currently, there are no licensed vaccines against either of these infectious diseases.

Amongst the relevant antigens for vaccine development against ETEC are the colonization factor (CF) antigens and the heat labile (LT) and heat stable (ST) enterotoxins. It has been proposed by experts that a multivalent vaccine containing 4-6 more common CF antigens, combined with LT, may provide protection against $80 \%$ ETEC strains globally $[41,42]$. In that regard, Dr. Thomas Wierzba from the Enteric Vaccine Initiative at PATH, discussed the status of vaccine development against ETEC-associated diarrhea emphasizing two of the lead candidates: ETVAX (Scandinavian Biopharma) and ACE527 (PATH), which have been found to be safe and immunogenic in Phase I/II trials.

On the other hand, among the 4-5 serotypes of Shigella spp. that have shown clinical importance, $S$. sonnei is highly prevalent globally and is the most frequent cause of traveler's shigellosis [43]. Dr. Audino Podda, Head of the Clinical Development \& Regulatory Affairs at Sclavo Behring Vaccines Institute for Global Health (Italia), described the advances of the vaccine candidate against $S$. sonnei based on Generalized Modules for Membrane Antigens (GMMA) and its evaluation in two Phase I dose escalation trials with encouraging results.

In contrast to Shigella and ETEC, oral cholera vaccines (OCV) against $V$. cholerae have existed since the 1980s. Currently, two WHO prequalified killed OCVs (Dukoral ${ }^{\circledR}$ and Shanchol ${ }^{\circledR}$ ) are available on the international market. Both have proved to be safe and effective; however, the development of other OCVs using attenuated live strains have continued in order to confer greater and longer-term protection after only one dose, especially in children under 5 years old [44]. In that regard, Dr. Rodrigo Valera (a specialist of clinical trials) at the Finlay Vaccine Institute, Cuba, presented the safety profile of the 638 attenuated strain, the Cuban vaccine candidate against cholera which has accomplished Phase I-II clinical trials in adults (National Clinical Trial Registry RPCEC00000188) and Phase I in children and adolescents of both sexes (National Clinical Trial Registry RPCEC00000172)

\section{Tuberculosis Vaccine}

The Tuberculosis (TB) Vaccines Symposium was focused on the presentation of important research on global TB epidemics and the efforts to develop new vaccines to prevent TB. The congress was honored to host a wide representation of International Foundations, Institutes and Universities, which carry out research and/or finance studies related to TB.

TB continues to be a central point of attention for many research groups worldwide. Even though the Bacille CalmetteGuerin (BCG) vaccine has been administered to thousands of people since 1921, it does not confer adequate protection against pulmonary infection in adults, as BCG has only definitively been shown to protect infants and young children from severe, often fatal complications of Mycobacterium tuberculosis (Mtb) infection [45]. Efforts to obtain a new vaccine that is more robust and efficient in protecting against Mtb infection than BCG, particularly in adolescents and adults, as these older age groups are the primary global source of Mtb transmission, represents a global health priority. At present, some vaccine candidates are in different clinical phase evaluation [46] (Table 1).

Prof. Hervé Bercovier, (Hebrew University of Jerusalem), spoke about BCG vaccination, its advantages and clinical applications both in humans and animals, not only for preventing TB infection, but also to understand the evolution of the disease as a way to fight against TB. Lewis Schrager, M.D, Vice-president of Scientific Affairs, AERAS, Maryland, USA, explained the status of the current development of TB vaccines, emphasizing the challenges and strategies related to this goal. Dr. Willem Hanekom, Deputy Director of TB Vaccines of Bill and Melinda Gates Foundation, USA, focused his presentation on the correlates of risk of TB disease, specifically describing ongoing efforts to discover new ways of developing and testing vaccine candidates against TB.

Prof. Edilberto Ochoa, Tropical Medicine Institute "Pedro Kourí", Cuba, shared the Cuban experience with TB to the conference, speaking about TB social inequalities in health both in developed and developing countries.

Subsequent speakers provided an in depth view into the efforts to develop specific TB vaccine candidates, including presentations illuminating preclinical advances being made in vaccine candidates derived from modifications of Mtb or related mycobacteria species. Dr Rogelio Hernández-Pando, M.D, pathologist from the National Institute of Medical Sciences and Nutrition "Salvador Zubirán" México, showed the potential use of an attenuated mutant of M. tuberculosis H37Rv lacking the sigma factor $\mathrm{E}$ as a live vaccine in an experimental model of progressive pulmonary TB in BALB/c mice infected by the intratracheal route. Dr. Hernández-Pando and his group demonstrated that non-vaccinated mice infected with a high dose of this mutant, showed higher survival rates and less tissue damage than animals infected with the parental strain. Although animals infected with the sigE mutant had low bacillary loads, their lungs showed significantly higher production of the protective factors interferon gamma (IFN- $\gamma$ ), tumor necrosis factor alpha (TNF- $\alpha$ ), inducible nitric oxide synthase (iNOS), and beta-defensins than those animals infected with the parental or 
complemented mutant strain [47]. Moreover, they demonstrated that the sigE mutant, when inoculated subcutaneously, was more attenuated than BCG in immunodeficient nude mice, and when used as a subcutaneous vaccine, induced a higher level of protection than did BCG after challenge with both $\mathrm{H} 37 \mathrm{Rv}$ and a highly virulent strain of M. tuberculosis (Beijing code 9501000). In order to get a more attenuated vaccine strain they produced a second mutation in the gene fadD26 that contributed to the production of the virulence factor phthiocerol dimycocerosates (DIM), producing the double sigE/fadD26 mutant (unpublished results). Using the same BALB/c mice model of progressive TB, they showed that the attenuation in fadD26 single mutant induced less tissue damage than the parental strain. When used as a subcutaneous vaccine, 60 days before intratracheal challenge with a hypervirulent strain of M. tuberculosis (Beijing code 9501000), this mutant induced a higher level of protection than did BCG. These findings suggested that this double mutant is a very promising strain for the development of a new vaccine against TB.

Dr Iliana Valdes, Tropical Medicine Institute "Pedro Kourí", Cuba, described her experiences using $M$. 'habana' as a vaccine candidate against TB. It is considered that the protection conferred by the vaccination with either a live, inactivated or protein fraction of M. 'habana' TMC- 5135 is probably related to less virulence signs in experimental models. M. 'habana' TMC- 5135 is a naturally attenuated strain which allows total animal survival and prevention of TB disease progression to a similar degree to BGG vaccination [48].

Yanely Tirado, Maria de los Angeles Garcia and Nadine Alvarez, Finlay Vaccine Institute of Cuba, showed the potential of proteoliposome and liposome formulations using non-pathogenic mycobacteria as promising candidates to be considered as a new vaccine strategy against TB infection [49]. OMV or proteoliposomes from mycobacteria were obtained using the experience and protocols developed by the Finlay Vaccine Institute to obtain OMV from meningococcus [50]. Due to the high homology between $M$. tuberculosis, M. smegmatis and BCG $[51,52]$ these results were not surprising in protecting against TB infection [53]. The candidates demonstrated the capacity to induce cellular and humoral immune responses and to recognize, via cross-reactivity, M. tuberculosis antigens modulated by the alum adjuvant $[54,55]$. Proteoliposome from M. smegmatis (unpublished results) and BCG [56] induced protection as a prophylactic vaccine against intratracheal infection with M. tuberculosis H37Rv, when they were administered with alum..

In addition to these presentations, other results were shared as poster presentations, including the protective capacity of liposomes obtained from M. smegmatis in BALB/c mice after challenge with the Mtb H37Rv strain [57]; the first Cuban report of anal TB in an AIDS patient [58]; surveillance of anti tuberculosis drug resistance in Cuba [59]; and preliminary results about the application of a phage-displayed human domain antibody library against cell wall lipoarabinomannan of M. tuberculosis.

This symposium represented a unique opportunity to

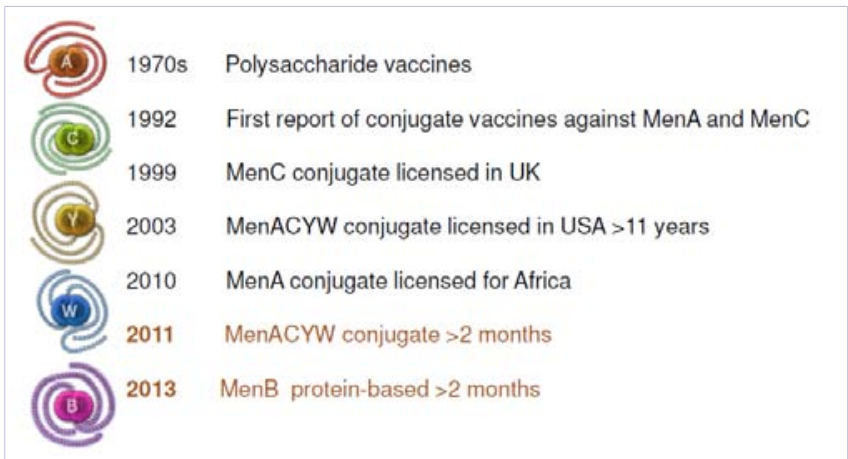

Figure 2: "A dream coming through"; in 2013 it became possible to prevent meningococcal disease caused by all major serogroups (adapted from Rino Rappuoli, presentation at EMGM September 2013).

interchange experiences, results, alternatives and strategies relevant to the evaluation of new TB vaccine candidates designed to address the disadvantages of BCG vaccination and to develop TB vaccines for use in adolescents and adults. Additionally, the congress provided an important opportunity to establish contacts, join efforts and work together to fight TB.

\section{Vaccines against meningococcal disease; status and perspectives}

The Meningoccocal Vaccine Symposium received prestigious researchers from scientific and health institutions, universities and pharma. The discussion was focused on the current situation of meningococcal vaccines, being the multivalent conjugated polysaccharide vaccines and the recently licensed antimeningococcal serogroup B vaccines. From the early capsular polysaccharide vaccines, developed in the late 1960s, there has been a gradual improvement in vaccines that have the bacterial polysaccharide (PS) capsule as the protective principle: first as purified PS vaccines against one serogroup, then as combinations for protection against an increased number of serogroups at the same time. More recently, the development of protein-PS conjugate vaccines and finally the quadrivalent conjugate formulations, against meningococcal serogroups A, C, Y and $\mathrm{W}$ have become some of the most important vaccine strategies ever implemented against these pathogens [60-63]. Important milestones and time points are listed in Figure 2. The public health impact of the various meningococcal vaccines has been great $[64,65]$. Dr Ray Borrow, Public Health England, UK referred to the evolving strategies for meningococcal conjugate vaccination, the importance of immunization schedules and concomitance studies to optimize the induction of immunological memory, protection and protective herd immunity against meningococcus.

The current R\&D situation of a pentavalent and thermostable vaccine against serogroups ACWY and X was presented by Dr. Marc LaForce (Serum Institute of India). Dr. LaForce also mentioned the impact of MenAfricVac immunization campaigns in some African countries. This conjugated vaccine against $N$. meningitidis serogroup A has become an affordable solution for developing countries of Africa against epidemics caused by this 
meningococcus $[66,67]$. Yet, further evaluation and clinical trials will be needed to demonstrate the impact of the new pentavalent vaccine candidate in Africa.

Nevertheless, for more than four decades there has been a challenging search for a vaccine against MenB disease [68,69]. Early on during the development of meningococcal vaccines, it was noticed that the MenB capsule was poorly immunogenic in humans due to molecular mimicry with glycoproteins found in human tissue (especially abundant in the fetal brain). Efforts to break immunological tolerance raised concerns regarding potential autoimmunity reactions and tissue damage in vaccinees in general and pregnant women in particular. Thus, vaccine development efforts in the MenB field have been concentrated on sub-capsular candidates $[68,70]$.

Dr Johan Holst, Norwegian Institute of Public Health (NIPH), Norway, opened the second session of the Meningoccocal Vaccine Symposium with a dissertation about the learning points from developing vaccines against MenB disease. In 1991, two large double-blind placebo-controlled clinical trials in Cuba and Norway demonstrated protection against the respective outbreak strain in these two countries. Due to the work of international collaborations, involving WHO, Pan American Health Organization (PAHO) and U.S Center for Disease Control and Prevention (CDC, Atlanta), it became clear that protection after primary immunization with two doses was of fairly short duration and a booster was needed after a year [71]. Also the protective immune response was directed mainly against the sero-subtype defining epitopes on PorA, a highly variable porine protein [72]. This phenomenon was most significant in infants, and OMV vaccines were deemed to be of only limited use against heterologous strains [73].

However, the international collaborations and exploratory efforts came to fruition when a serious outbreak of MenB disease appeared in New Zealand in the beginning of the 1990s [74]. The solution for this problem was to make an OMV vaccine based on that particular circulating strain [75]. During the situation in New Zealand it was declared unethical to perform a placebocontrolled trial, so after initial safety and immunogenicity studies, the vaccine was offered in a three-dose schedule to all 1.3 million inhabitants less than 20 years of age (later four doses for infants) $[70,75]$. Effectiveness estimates of $73 \%$ for all age groups over a two-year observation period were found retrospectively, because the staggered roll-out of the vaccine in the population resulted in vaccinated and un-vaccinated cohorts existing at the same time $[70,76]$.

In the search for a more universal vaccine with broad strain coverage, a number of approaches have been explored; from multi-valented PorA based OMV vaccines to single "crossreactive" antigens as lipopolysaccharides (LPS) and various minor outer membrane proteins that were assumed to be under less immunological pressure than PorA [68, 69, 77]. The first substantial breakthrough occurred in 2000 by sequencing the whole genome of a $N$. meningitidis strain and using the in silico mining approach, named Reverse Vaccinology [78]. The vaccine developed according to these principles was ready 13 years later for licensure and global use under the name $4 \mathrm{CMenB}$ (Bexsero ${ }^{\circledR}$, Novartis later GSK) $[77,79]$. The active principle of this vaccine consists of three recombinant proteins: factor H-binding protein (fHbp), neisserial heparin-binding antigen (NHBA) and neisserial adhesin $\mathrm{A}(\mathrm{NadA})$ in combination with an OMV component (with the PorA porine P1.4) [77, 79]. The latter is in fact the same vaccine component that was used for controlling the outbreak in New Zealand during the nation-wide campaign from 2004 to 2008, mentioned above.

In parallel, a more traditional approach, consisting of fractionation of bacterial extracts and immunological measurements, led to the development of another protein based MenB vaccine, rLP2086 with the commercial name Trumenba ${ }^{\circledR}$ (Wyeth/Pfizer) [80, 81]. This vaccine formulation consists of two lipidated variants of fHbp, which are claimed to cover most circulating MenB strains. Both formulations contain fHbp as a key protective antigen and have demonstrated broad strain coverage in the range of $70 \%$ to $90 \%$, depending on the actual local epidemiological situation [82-84].

In 2013, a long-anticipated goal was reached with the licensure of the first vaccine with the ability to prevent against most circulating serogroup B of $N$. meningitidis (MenB) (http://centerforvaccineethicsandpolicy.net/2012/11/24/ ema-recommends-marketing-authorization-for-bexsero mening-b-novartis and http://www.ema.europa.eu/ema/ index.jsp?curl=pages/medicines/human/medicines/002333/ human_med_001614.jsp\&mid=WC0b01ac058001d124).

The first universal MenB vaccine on the market (in EU) was named $4 \mathrm{CMenB}$ with the commercial name Bexsero ${ }^{\circledR}$, from Novartis. In 2014 another MenB vaccine was licensed in USA, called Trumenba ${ }^{\circledR}$ (rLP2086,Pfizer)(http://www.fda. gov/BiologicsBloodVaccines/Vaccines/ApprovedProducts/ ucm421020.htm). Thus, the vision of vaccinating against all major disease-causing serogroups of meningococci is now a possibility [85].

Development of these more universal MenB vaccines required more than 20 years of research, and they represent a solid breakthrough for the prevention of MenB disease globally. These vaccines are also the first protein-based bacterial vaccines that are not dependenton toxin neutralization as a key preventive principle. This historical use and integration of knowledge in the field of vaccinology will also prove important for development of other vaccines in the years to come. Learning points that will be particularly useful, also in more general settings, include selection of strain panels and evaluation of strain coverage for a particular vaccine formulation. Challenges of making the selected vaccine candidates sufficiently immunogenic and cross-reactive can profit from the developmental experience for 4CMenB and rLP2086. In addition to the scientific issues, MenB development and the initial attempts to implement the vaccine in national vaccination programs, also illustrated limitations with the current models for cost-effectiveness and thus difficulties for decision makers to appreciate the true value of vaccines against rare, but very serious infectious diseases [86, 
87]. However, from September 2015 Bexsero ${ }^{\circledR}$ was introduced in the UK childhood immunization program (http://www.meningitis. org/menb-vaccine;

http://www.fiercevaccines.com/story/gsk-finally-seals-ukbexsero-deal-20-dose/2015-03-30) [88].

It will take at least two to five years until we know the full clinical impact and value of these new meningococcal vaccines in various epidemiological situations. Issues to be studied more carefully are duration of protection in various age groups, mucosal immunity and herd protection. Of particular note, a substantial difference in immunogenicity has been observed with recombinant $\mathrm{fHbp}$ versus the experimental formulations of native $\mathrm{OMV}$ vaccines where fHbp has been included as over-expressed vaccine antigen (NOMV-OEfHbp with 3-6 times the ordinary level found in wild type strains) [89-91]. The total amount of fHbp in the two formulations can be more than 100 times different, and the NOMV formulation induces better anti-fHbp immunity than the recombinant vaccine. Since fHbp is a membrane-attached lipoprotein the NOMV must be manufactured without using the standard detergent extraction established for manufacture of ordinary OMV vaccines [92]. Instead the vaccine can be made tolerable for humans with genetic manipulation of LPS (lpx1-mutants) [89]. Preclinical studies with NOMV vaccines have shown higher protective titres and broader immune responses, resulting in better capacity to kill strains with fHbp variants that are substantially different from the vaccine antigen selected for the vaccine [91,93-95]. These observations served as inspiration for further studies of the OMV-concept and use of NOMV as a "platform" for various other antigens. This approach might also well provide benefits in the fight against diseases that are in need for better-performing vaccines, like Bordetella pertussis [96] or where so far there are no other vaccine alternatives in existence, against like S. sonnei [97].

Even so, the applications of detergent extracted OMV are ongoing. The results of a collaborative project between Finlay Vaccine Institute and NIPH was presented by Dr Luis Garcia (Cuba), Dr Einar Rosenqvist (Norway) and Dr Lisbeth Naess (Norway). The Phase I clinical trial using a bivalent OMV formulation from meningococcal serogroups $\mathrm{A}$ and $\mathrm{W}$ demonstrate that the candidate was safe (National Clinical Trial Registry RPCEC00000160). Moreover, satisfactory preclinical results using a trivalent $\mathrm{OMV}$ combination against $\mathrm{A}, \mathrm{W}$ and $\mathrm{X}$ serogroups was discussed as an alternative to developing an affordable vaccine for African countries [98].

Thus, in the current situation there are strong indications for continued development and use of the OMV-concept in various ways for modern biotechnology and vaccinology, in the decades to come (Figure 2).

\section{Improving vaccination for all people}

A general Symposium was dedicated to review recent strategies for the sustainable development of vaccines. Dr. Pagliusi, Executive Secretary of Developing Countries Vaccine Manufacturers' Network (DCVMN), Switzerland explained how DCVMN stands for improving vaccination to all people: The common mission of all DCVMN members is to protect people against known and emerging infectious diseases, by improving the availability of high-quality vaccines globally. As an international, nongovernmental, non-partisan, not-for-profit, public health driven alliance of vaccine manufacturers, research and policy organizations from all over the world, it operates based on principles of sharing knowledge for international scientific, technical and economic cooperation, guided by common values of equity, responsibility, accountability, transparency and respect.

Developing countries' economies include all countries that

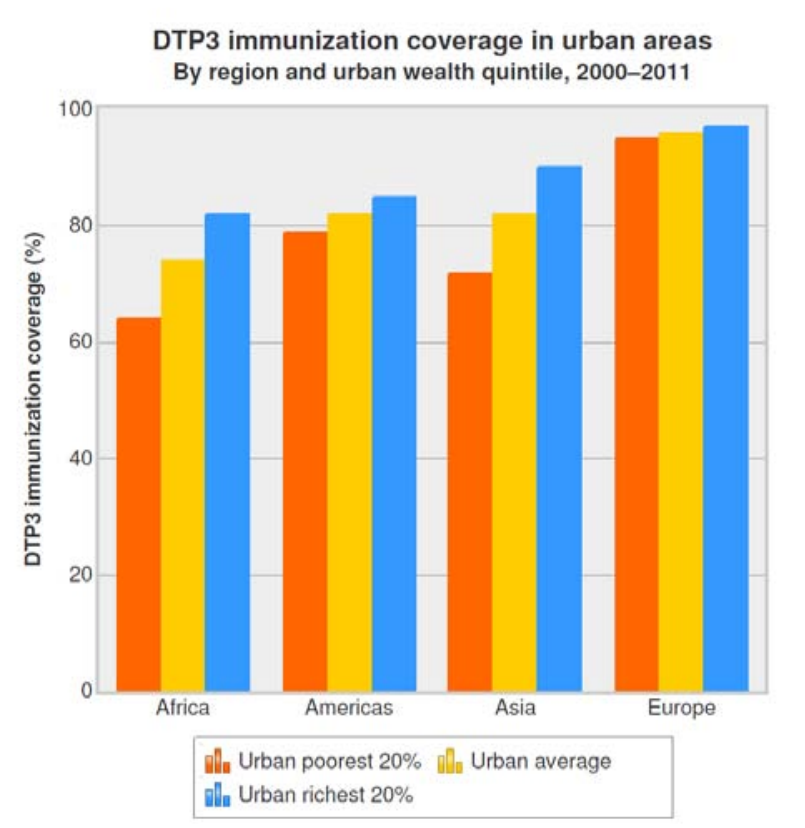

Figure 3: The results represent averages of those countries for which urban Demographic and Health Surveys (DHS) data were available for coverage of child DPT3 vaccination during 2000-2011 (Africa $=31$ countries, Americas $=8$ countries, Asia $=14$ countries, Europe $=2$ countries).

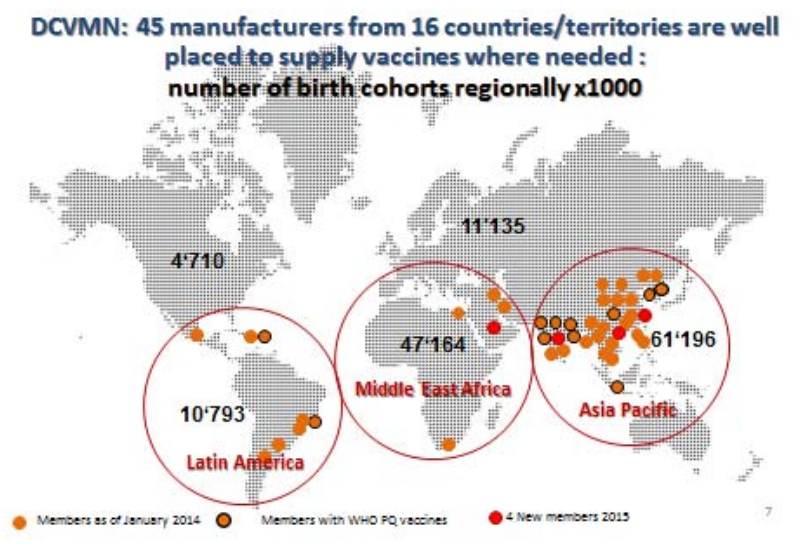

Figure 4: Graphic representations of manufacturers and countries working together to carry out vaccination for all people 
reach a specific level of human development for their respective populations according to the Human Development Index (HDI) of the International Monetary Fund (World Economic Outlook 2015, IMF cf. http://www.imf.org/external/pubs/ft/weo/2015/01/ $\mathrm{pdf} /$ text.pdf) based on three main criteria: economic, education and health status (Figure 3). Thus, except for North American, most central European, Oceania countries and Japan, all other countries are considered developing economies. Thus, the network is composed of 45 corporate members located in 16 countries or territories, divided in three major regions: Latin America with 8 manufacturers, Middle-East-Africa with 5 manufacturers, and AsiaPacific with 32 manufacturers, and well positioned to serve the respective regional populations. All manufacturers operate with the approval of local regulatory authorities and 11 manufacturers have vaccines prequalified by WHO, for global procurement. The challenge is to satisfy the needs of developing country populations, which represent approximately $80 \%$ of the world's population and is growing at a fast pace with high birth rates in many countries, with 1 billion people growing from 2000 to 2012, and estimated to reach 8 billion by 2025 . Thus, the demand for protective vaccines are on the rise, particularly in developing countries, where DTP coverage as an indicator is at around $80 \%$ in average in Africa and Asia compared to $95 \%$ coverage in industrialized regions as exemplified by European region (Figure 4).

In addition to supplying vaccines for national public immunization programs, the manufacturers have contributed significantly to major global health initiatives such as polio eradication, tetanus elimination, measles and rubella elimination, and to supply vaccines such as yellow fever, typhoid fever, meningitis A, Japanese encephalitis, and Hepatitis E vaccines, diseases predominantly relevant on a regional basis.

By sharing the common goals of increasing and maintaining the number of vaccines available for international procurement, particularly for GAVI-eligible countries, while reducing the time to obtaining WHO prequalification $\mathrm{PQ}$, and securing sustainable vaccines supply, the Network has launched four initiatives to support manufacturers, as follows: 1) review the design and layout of manufacturing facilities and systems as to fulfill global GMP expectations; 2) Training workshops, to update professionals on

Table 1: Current vaccine candidates against TB in clinical phase evaluation

\begin{tabular}{|l|l|l|l|}
\hline Phase I & Phase II & Phase IIIb & Phase III \\
\hline AdAg85A & VPM 1002 & MVA85A & M. Vaccae \\
MTBVAC & H1+IC31 & M72+AS01 & \\
ID93+GLA-SE & RUTI & \\
Crucell Ad35/ & H56:IC31 & \\
MVA85A & H4:IC31 & \\
DAR901 & CrucellAd35/ \\
TE/FLU-04L & AERAS-402
\end{tabular}

recent Good Practices in may areas (GXP) and PQ requirements; 3) create a forum for industry to discuss regulatory challenges with experts; 4) to create a database of expert vaccine consultants for corporate organizations to advance specific projects' needs. The new initiatives are expected to have an impact on upgrading facilities for priority vaccines, provide consistent information to industry professionals from developing countries on GMP, quality management systems and pre-qualification, serving as "harmonization" efforts, unlocking new regulatory approaches to improve access to vaccines to benefit people in developing countries, and facilitate access to reliable consulting expertise for members to advance with clinical development, regulatory dossiers, partnerships and investments. DCVMN has focused efforts in trying to engage members and partners in contributing to the global initiatives.

Notably, the demand and supply for the 5-in-1 pentavalent vaccines in developing countries has grown 10 fold in the last 10 years, from 20 to 200 million doses procured by UNICEF, due to availability from over 6 manufacturers, and all 73 GAVI countries have introduced this vaccine today as compared to 5-6 countries in 2004. The goal is that the same pattern proves true for rotavirus, pneumococcal and HPV vaccines, among others, when more manufacturers can make them available. Vaccines have proven to be an effective strategy in controlling, eliminating and eradicating infectious diseases, as a result of close cooperation and partnerships.

Still much remains to be achieved, as while the global coverage of essential traditional vaccines such as DTP, hepatitis B, measles and polio averaged $84 \%$ global coverage in 2013 , the new vaccines such as pneumococcal and rotavirus vaccines is of 25 and 14\% respectively, and HPV and other vaccines even less. The needs are huge as populations in developing countries continue to grow and so we need strong manufacturers to take up this challenge and scale up the supply of affordable vaccines to control and prevent the spread of infectious diseases globally.

DCVMN has focused efforts in trying to engage members and partners in contributing to the global initiatives.

\section{References}

1. Poolman JT. Shortcomings of pertussis vaccines: Why we need a third generation vaccine. Expert review of vaccines. 2014;13(10):11591162.

2. Allen AC, Mills KH. Improved pertussis vaccines based on adjuvants that induce cell-mediated immunity. Expert review of vaccines. 2014;13(10):1253-1264.

3. Robbins JB, Schneerson R, Kubler-Kielb J, Keith JM, Trollfors B, Vinogradov E, et al. Toward a new vaccine for pertussis. Proceedings of the National Academy of Sciences of the United States of America. 2014;111(9):3213-3216.

4. Dias WO, van der ArkAA, Sakauchi MA, Kubrusly FS, Prestes AF, Borges $\mathrm{MM}$, et al. An improved whole cell pertussis vaccine with reduced content of endotoxin. Human vaccines \& immunotherapeutics. 2013;9:339-348.

5. Raeven RH, van der Maas L, Tilstra W, Uittenbogaard JP, Bindels TH, Kuipers B, et al. Immunoproteomic profiling of bordetella pertussis 
outer membrane vesicle vaccine reveals broad and balanced humoral immunogenicity. Journal of proteome research. 2015;14(7):2929-2942.

6. Gaillard ME, Bottero D, Errea A, Ormazabal M, Zurita ME, Moreno G, et al. Acellular pertussis vaccine based on outer membrane vesicles capable of conferring both long-lasting immunity and protection against different strain genotypes. Vaccine. 2014;32(8):931-937.

7. Hendriksen CF. Refinement, reduction, and replacement of animal use for regulatory testing: Current best scientific practices for the evaluation of safety and potency of biologicals. ILAR journal / National Research Council, Institute of Laboratory Animal Resources. 2002;43 (Suppl:S43-48).

8. Hendriksen CF. Replacement, reduction and refinement alternatives to animal use in vaccine potency measurement. Expert review of vaccines. 2009;8(3):313-322.

9. Chovel ML, Mandiarote A, Ontivero I, Mahy T, Herrera L, Francisco J, et al. Development of 3rs alternatives for determining potency and toxicity of vaccines in cuba: Current challenges and research projects in progress. Altex. 2012; Proceedings, 1/12

10. O’Brien KL, Wolfson LJ, Watt JP, Henkle E, Deloria-Knoll M, McCall N, et al. Pneumococcal Global Burden of Disease Study T. Burden of disease caused by streptococcus pneumoniae in children younger than 5 years: Global estimates. Lancet. 2009;374(9693):893-902.

11. Black S, Shinefield H, Fireman B, Lewis E, Ray P, Hansen JR, et al. Efficacy, safety and immunogenicity of heptavalent pneumococcal conjugate vaccine in children. Northern california kaiser permanente vaccine study center group. The Pediatric infectious disease journal. 2000;19(3):187-195

12. Redelings MD, Sorvillo F, Simon P, Mascola L. Declining early childhood mortality from invasive pneumococcal disease: The impact of vaccination. Archives of pediatrics \& adolescent medicine 2005;159(2):195-196

13. GAVI. Advance market commitment for pneumococcal vaccines. Annual report: 1 april $2014-31$ march 2015.

14. Publication WHO. Pneumococcal vaccines who position paper - 2012 recommendations. Vaccine. 2012;30:4717-4718.

15. Whitney CG, Goldblatt D, O’Brien KL. Dosing schedules for pneumococcal conjugate vaccine: Considerations for policy makers. The Pediatric infectious disease journal .2014;33 (Suppl 2:S172-181).

16. Domingues CM, Verani JR, Montenegro Renoiner EI, de Cunto Brandileone MC, Flannery B, de Oliveira LH, etal. Brazilian Pneumococcal Conjugate Vaccine Effectiveness Study G. Effectiveness of ten-valent pneumococcal conjugate vaccine against invasive pneumococcal disease in brazil: A matched case-control study. The Lancet Respiratory medicine .2014;2(6):464-471.

17. Andrews NJ, Waight PA, Burbidge P, Pearce E, Roalfe L, Zancolli M, et al. Serotype-specific effectiveness and correlates of protection for the 13-valent pneumococcal conjugate vaccine: A postlicensure indirect cohort study. The Lancet Infectious diseases .2014;14(9):839-846.

18. Cutts FT, Zaman SM, Enwere G, Jaffar S, Levine OS, Okoko JB,et al. Gambian Pneumococcal Vaccine Trial G. Efficacy of nine-valent pneumococcal conjugate vaccine against pneumonia and invasive pneumococcal disease in the gambia: Randomised, double-blind, placebo-controlled trial. Lancet .2005;365(9465):1139-1146.

19. Klugman KP, Madhi SA, Huebner RE, Kohberger R, Mbelle N, Pierce N, Vaccine Trialists G. A trial of a 9-valent pneumococcal conjugate vaccine in children with and those without hiv infection. The New England journal of medicine. 2003;349:1341-1348
20. Weinberger DM, Harboe ZB, Sanders EA, Ndiritu M, Klugman KP, Ruckinger $\mathrm{S}$, et al. Association of serotype with risk of death due to pneumococcal pneumonia: A meta-analysis. Clinical infectious diseases : an official publication of the Infectious Diseases Society of America. 2010;51(6):692-699.

21. Ruckinger S, Dagan R, Albers L, Schonberger K, von Kries R. Immunogenicity of pneumococcal conjugate vaccines in infants after two or three primary vaccinations: A systematic review and metaanalysis. Vaccine .2011;29(52):9600-9606.

22. Flasche S, Van Hoek AJ, Goldblatt D, Edmunds WJ, O’Brien KL, Scott JA, et al. The potential for reducing the number of pneumococcal conjugate vaccine doses while sustaining herd immunity in highincome countries. PLoS medicine. 2015;12(6):e1001839.

23.GAVI. Target product profile (tpp) for the advance market commitment. (amc) for pneumococcal conjugate vaccines (part 1), master table. Geneva: World health organization 2008.

24. Leroux-Roels G, Maes C, De Boever F, Traskine M, Ruggeberg JU, Borys D. Safety, reactogenicity and immunogenicity of a novel pneumococcal protein-based vaccine in adults: A phase i/ii randomized clinical study. Vaccine. 2014;32(50):6838-6846.

25. Prymula R, Pazdiora P, Traskine M, Ruggeberg JU, Borys D. Safety and immunogenicity of an investigational vaccine containing two common pneumococcal proteins in toddlers: A phase ii randomized clinical trial. Vaccine 2014;32(25):3025-3034.

26. Pauksens K, Nilsson AC, Caubet M, Pascal TG, Van Belle $P$, Poolman JT, et al.Randomized controlled study of the safety and immunogenicity of pneumococcal vaccine formulations containing phtd and detoxified pneumolysin with alum or adjuvant system as $02 \mathrm{v}$ in elderly adults. Clinical and vaccine immunology : CVI 2014;21(5):651-660.

27.Verez-Bencomo V, Fernandez-Santana V, Hardy E, Toledo ME, Rodriguez MC,et al. A synthetic conjugate polysaccharide vaccine against haemophilus influenzae type b. Science .2004;305(5683):522-525.

28. González N, Paredes B, Pérez S, Mirabal M, Rivero I, González CA, et al. Clinical trial of safety and immunogenicity of cuban investigational antipneumoccal vaccine vcn7-t in healthy adults. MEDICC Review. 2015;17(4):32-37.

29. Dotres CP, Puga R, Ricardo Y, Brono CR, Paredes B, Echemendia V, et al.Laboratory-Pneumococci G, Havana-Pneumococci G. Safety and preliminary immunogenicity of cuban pneumococcal conjugate vaccine candidate in healthy children: A randomized phase i clinical trial. Vaccine. 2014;32(41):5266-5270.

30. Basta NE, Borrow R, Berthe A, Dembele AT, Onwuchekwa U, Townsend $\mathrm{K}$, et al. Population-level persistence of immunity 2 years after the psa-tt mass-vaccination campaign in mali. Clinical infectious diseases : an official publication of the Infectious Diseases Society of America. 2015;61 (Suppl 5):S547-553.

31. Tall H, Yaro S, Kpoda HB, Ouangraoua S, Trotter CL, Njanpop Lafourcade BM, et al. Meningococcal seroepidemiology 1 year after the psa-tt mass immunization campaign in burkina faso. Clinical infectious diseases : an official publication of the Infectious Diseases Society of America .2015;61 (Suppl 5):S540-546.

32. WHO. Foodborne enteric disease affects 600 million, kills 351,000 in 2010.

33. Nataro JP. Vaccines against diarrheal diseases. Semin Pediatr Infect Dis. 2004;15(4):272-279. 
34. Crump JA, Mintz ED. Global trends in typhoid and paratyphoid fever. Clinical infectious diseases : an official publication of the Infectious Diseases Society of America .2010;50(2):241-246.

35. WHO. Typhoid vaccines: Who position paper no6. Weekly Epidemiological Report. 2008;83(6):49-60.

36. MacLennan CA, Martin LB, Micoli F. Vaccines against invasive salmonella disease, current status and future directions. Human vaccines \& immunotherapeutics .2014;10(6):1478-1493.

37. Typhoid CA. Current typhoid vaccines. 2016.

38. WHO. Diarrhoeal disease. Fact sheet no. 330.

39. Lanata CF, Fischer-Walker CL, Olascoaga AC, Torres CX, Aryee MJ, Black RE. Global causes of diarrheal disease mortality in children $<5$ years of age: A systematic review. PloS one. 2013;8:e72788.

40.WHO. Future directions for research on enterotoxigenic escherichia coli vaccines for developing countries. Weekly Epidemiological Report

41. Ahren CM, Svennerholm AM. Synergistic protective effect of antibodies against escherichia coli enterotoxin and colonization factor antigens. Infection and immunity. 1982;38:74-79.

42. Wolf MK. Occurrence, distribution, and associations of $\mathrm{o}$ and $\mathrm{h}$ serogroups, colonization factor antigens, and toxins of enterotoxigenic escherichia coli. Clin Microbiol Rev.1997;10:569-584.

43. Ekdahl K, Andersson Y. The epidemiology of travel-associated shigellosis-regional risks, seasonality and serogroups. The Journal of infectious diseases. 2005;51(3):222-229.

44. Ryan ET, Calderwood SB, Qadri F. Live attenuated oral cholera vaccines. Expert review of vaccines. 2006;5(4):483-494.

45. Montagnani C, Chiappini E, Galli L, de Martino M. Vaccine against tuberculosis: What's new? BMC infectious diseases 2014;14( Suppl 1):S2.

46. WHO. Global tuberculosis report 2014.

47. Hernandez Pando R, Aguilar LD, Smith I, Manganelli R. Immunogenicity and protection induced by a mycobacterium tuberculosis sige mutant in a balb/c mouse model of progressive pulmonary tuberculosis. Infection and immunity. .2010;78(7):3168-3176.

48. Valdés I, Echemendía M, Mederos LM, Valdivia JA, Montoro E. Aspectos relevantes del uso de mycobacterium 'habana' como candidato vacunal contra la tuberculosis. Vaccimonitor .2011;20(3):34-39.

49. Acosta A, Norazmi MN, Puig A, Kadir R, Reyes F, Tirado Y. Tb vaccines based on proteoliposomes and liposomes from nonpathogenic mycobacteria. In: Norazmi MN, Acosta A, Sarmiento ME, eds. The art \& science of tuberculosis vaccine development: Malaysia Oxford University Press, 2014: pp 783-793.

50. Sierra GV, Campa HC, Varcacel NM, Garcia IL, Izquierdo PL, Sotolongo PF, Casanueva GV, Rico CO, Rodriguez CR, Terry MH. Vaccine against group b neisseria meningitidis: Protection trial and mass vaccination results in cuba. NIPH annals. 1991;14(2):195-207; discussion 208-110.

51. Garnier T, Eiglmeier K, Camus JC, Medina N, Mansoor H, Pryor M, et al.The complete genome sequence of mycobacterium bovis. Proceedings of the National Academy of Sciences of the United States of America. .2003;100(13):7877-7882.

52. Reyrat JM, Kahn D. Mycobacterium smegmatis: An absurd model for tuberculosis? Trends in microbiology .2001;9(10):472-473.

53. Alvarez N, Fernández S, Serpa D, Serrano D, Zayas C, Cabrera R.
Avances en la caracterización de un proteoliposoma derivado de mycobacterium bovis bcg como candidato vacunal contra la tuberculosis. Vaccimonitor. 2014;23(3):110-116.

54. Reyes F, Tirado Y, Puig A, Borrero R, Reyes G, Fernandez S, et al. Immunogenicity and cross-reactivity against mycobacterium tuberculosis of proteoliposomes derived from mycobacterium bovis bcg. BMC immunology 2013;14 (Suppl 1:S7.

55. Rodriguez L, Tirado Y, Reyes F, Puig A, Kadir R, Borrero R, et al. Proteoliposomes from mycobacterium smegmatis induce immune cross-reactivity against mycobacterium tuberculosis antigens in mice. Vaccine. 2011;29(37):6236-6241.

56. Tirado Y, Puig A, Alvarez N, Borrero R, Aguilar A, Camacho F, et al. Protective capacity of proteoliposomes from mycobacterium bovis bcg in a mouse model of tuberculosis. Human vaccines \& immunotherapeutics. 2015;11(3):657-661.

57. Garcia Mde L, Borrero R, Lanio ME, Tirado Y, Alvarez N, Puig A, et al. Protective effect of a lipid-based preparation from mycobacterium smegmatis in a murine model of progressive pulmonary tuberculosis. BioMed research international 2014;2014:273129.

58. Mederos LM, Fleites G, Acosta MA, Valdés L, Calás V, Martinez MR. Tuberculosis anal en paciente con síndrome de inmunodeficiencia adquirida (sida). Síndrome Cardiometabólico. 2012;11:48-51.

59. Lemus D, Echemendía M, Díaz R, Llop A, Llanes MJ. Vigilancia de la resistencia a los medicamentos antituberculosos en cuba, 20102011. Biomédica. 2014;34:108-113.

60. Gotschlich EC, Goldschneider I, Artenstein MS. Human immunity to the meningococcus. Iv. Immunogenicity of group a and group c meningococcal polysaccharides in human volunteers. J Exp Med .1969;129(6):1367-1384.

61. Hankins WA, Gwaltney JM, Jr., Hendley JO, Farquhar JD, Samuelson JS. Clinical and serological evaluation of a meningococcal polysaccharide vaccine groups a, c, y, and w135. Proc Soc Exp Biol Med. 1982;169(1):54-57.

62. Rennels MB, Edwards KM, Keyserling HL, Reisinger K, Blatter MM, Quataert SA, et al. Safety and immunogenicity of four doses of neisseria meningitidis group c vaccine conjugated to crm197 in united states infants. Pediatr Infect Dis J. 2001;20(2):153-159.

63. Keyserling H, Papa T, Koranyi K, Ryall R, Bassily E, Bybel MJ, et al. Safety, immunogenicity, and immune memory of a novel meningococcal (groups a, c, y, and w-135) polysaccharide diphtheria toxoid conjugate vaccine (mcv-4) in healthy adolescents. Arch Pediatr Adolesc Med. 2005;159(10):907-913.

64. Gasparini R, Panatto D. Meningococcal glycoconjugate vaccines. Hum Vaccin .2011;7(2):170-182.

65. Granoff DM, Harrison L, Borrow R. Meningoccal vaccines. In: Plotkin SA, Offit P, Orenstein WA, eds. Vaccines, 5th edition Philadelphia: Saunders Elsevier, 2008: pp 399-434.

66. Karachaliou A, Conlan AJ, Preziosi MP, Trotter CL. Modeling long-term vaccination strategies with menafrivac in the african meningitis belt. Clinical infectious diseases : an official publication of the Infectious Diseases Society of America. 2015;61 (Suppl 5):S594600 .

67. Tapia MD, Findlow H, Idoko OT, Preziosi MP, Kulkarni PS, Enwere GC,et al. Antibody persistence 1-5 years following vaccination with menafrivac in african children vaccinated at 12-23 months of age. Clinical infectious diseases : an official publication of the Infectious 


\section{Diseases Society of America. 2015;61 (Suppl 5):S514-520}

68. Granoff DM. Review of meningococcal group b vaccines. Clin Infect Dis. 2010;50 (Suppl 2):S54-65.

69. Sadarangani M, Pollard AJ. Serogroup b meningococcal vaccines-an unfinished story. Lancet Infect Dis. 2010;10(2):112-124.

70. Holst J, Oster P, Arnold R, Tatley MV, Naess LM, Aaberge IS, Galloway Y, McNicholas A, O'Hallahan J, Rosenqvist E, Black S. Vaccines against meningococcal serogroup $b$ disease containing outer membrane vesicles (omv): -lessons from past programs and implications for the future. Hum Vaccin. 2013;9(6):1241-1253

71. Holst J, Martin D, Arnold R, Huergo CC, Oster P, O'Hallahan J, et al. Properties and clinical performance of vaccines containing outer membrane vesicles from neisseria meningitidis. Vaccine. 2009;27 (Suppl 2):B3-12.

72. Tappero JW, Lagos R, Ballesteros AM, Plikaytis B, Williams D, Dykes J,et al. Immunogenicity of 2 serogroup $\mathrm{b}$ outer-membrane protein meningococcal vaccines: A randomized controlled trial in chile. JAMA. 1999;281(16):1520-1527.

73. Wenger JD. Serogroup b meningococcal disease: New outbreaks, new strategies. JAMA. 1999;281(16):1541-1543.

74. Martin DR, Walker SJ, Baker MG, Lennon DR. New zealand epidemic of meningococcal disease identified by a strain with phenotype b:4:P1.4. J Infect Dis. 1998;177(2):497-500.

75. O'Hallahan J, Lennon D, Oster P, Lane R, Reid S, Mulholland K, et al. From secondary prevention to primary prevention: A unique strategy that gives hope to a country ravaged by meningococcal disease. Vaccine. 2005;23(17-18):2197-2201.

76. Arnold R, Galloway Y, McNicholas A, O'Hallahan J. Effectiveness of a vaccination programme for an epidemic of meningococcal $b$ in new zealand. Vaccine. 2011;29(40):7100-7106.

77. Pizza M, DeTora L, Wassil J. Advances in meningococcal vaccines. Clin Pract. 2012;9(1):101-117.

78. Pizza M,Scarlato V, Masignani V, Giuliani MM,Arico B, Comanducci M, etal. Identification of vaccine candidates against serogroup b meningococcus by whole-genome sequencing. Science. 2000;287(5459):1816-1820.

79. Giuliani MM, Adu-Bobie J, Comanducci M, Arico B, Savino S, Santini L, et al. A universal vaccine for serogroup b meningococcus. Proc Natl Acad Sci U S A . 2006;103(29):10834-10839.

80. Fletcher LD, Bernfield L, Barniak V, Farley JE, Howell A, Knauf M, et al. Vaccine potential of the neisseria meningitidis 2086 lipoprotein. Infect Immun .2004;72(4):2088-2100.

81. Zlotnick GW, Jones TR, Liberator P, Hao L, Harris S, McNeil LK,et al. The discovery and development of a novel vaccine to protect against neisseria meningitidis serogroup $\mathrm{b}$ disease. Human vaccines \& immunotherapeutics. 2015;11(1):5-13.

82. Donnelly J, Medini D, Boccadifuoco G, Biolchi A, Ward J, Frasch C, et al. Qualitative and quantitative assessment of meningococcal antigens to evaluate the potential strain coverage of protein-based vaccines. Proc Natl Acad Sci U S A .2010;107(45):19490-19495.

83. Vogel U, Taha MK, Vazquez JA, Findlow J, Claus H, Stefanelli P, et al. Predicted strain coverage of a meningococcal multicomponent vaccine ( $4 \mathrm{cmenb})$ in europe: A qualitative and quantitative assessment. Lancet Infect Dis. 2013;13(5):416-425.
84. Jiang HQ, Hoiseth SK, Harris SL, McNeil LK, Zhu D, Tan C, et al. Broad vaccine coverage predicted for a bivalent recombinant factor $h$ binding protein based vaccine to prevent serogroup $\mathrm{b}$ meningococcal disease. Vaccine. .2010;28(37):6086-6093.

85. Black S, Pizza M, Nissum M, Rappuoli R. Toward a meningitis-free world. Science translational medicine. 2012;4:123,pp.123ps5.

86. Moxon R, Snape MD. The price of prevention: What now for immunisation against meningococcus b? Lancet. .2013;382(9890):369-370.

87. Mekalanos JJ. Vaccine economics: What price human life? Science translational medicine 2013;5(204):pp204ed16.

88. Andrews SM, Pollard AJ. A vaccine against serogroup b neisseria meningitidis: Dealing with uncertainty. Lancet Infect Dis .2014;14(5):426-434.

89. Koeberling 0, Seubert A, Granoff DM. Bactericidal antibody responses elicited by a meningococcal outer membrane vesicle vaccine with overexpressed factor h-binding protein and genetically attenuated endotoxin. J Infect Dis. 2008;198(2):262-270.

90. Koeberling 0, Delany I, Granoff DM. A critical threshold of meningococcal factor $\mathrm{h}$ binding protein expression is required for increased breadth of protective antibodies elicited by native outer membrane vesicle vaccines. Clin Vaccine Immunol. 2011;18(5):736742

91. Pajon R, Fergus AM, Koeberling O, Caugant DA, Granoff DM. Meningococcal factor $\mathrm{h}$ binding proteins in epidemic strains from africa: Implications for vaccine development. PLoS neglected tropical diseases. 2011;5:e1302.

92. Frasch C, Van Alphen L, Holst J, Poolman J, Rosenqvist E. Outer membrane protein vesicle vaccines for meningococcal disease. In: Pollard AJ, Maiden MC, eds. Meningococcal vaccines: Methods and protocols. Totowa, New Jersey: Humana Press, 2001: pp 81-107.

93. Koeberling O, Ispasanie E, Hauser J, Rossi O, Pluschke G, Caugant DA, et al. A broadly-protective vaccine against meningococcal disease in sub-saharan africa based on generalized modules for membrane antigens (gmma). Vaccine. .2014;32(23):2688-2695.

94. Keiser PB, Biggs-Cicatelli S, Moran EE, Schmiel DH, Pinto VB, Burden $\mathrm{RE}$,et al. A phase 1 study of a meningococcal native outer membrane vesicle vaccine made from a group $b$ strain with deleted lpxl1 and synx, over-expressed factor $\mathrm{h}$ binding protein, two poras and stabilized opca expression. Vaccine .2011;29(7):1413-1420.

95. Pinto VB, Moran EE, Cruz F, Wang XM, Fridman A, Zollinger WD, Przysiecki CT, Burden R. An experimental outer membrane vesicle vaccine from $\mathrm{n}$. Meningitidis serogroup $\mathrm{b}$ strains that induces serum bactericidal activity to multiple serogroups. Vaccine .2011;29(44):7752-7758.

96. Gorringe AR. The difficult road to new vaccines for pertussis and serogroup b meningococcal disease. J Chem Technol Biotechnol. 2015:7.

97. Gerke C, Colucci AM, Giannelli C, Sanzone S, Vitali CG, Sollai L,et al. Production of a shigella sonnei vaccine based on generalized modules for membrane antigens (gmma), 1790gahb. PLoS One .2015;10(8): 0134478 .

98. Tunheim G, Naess LM, Acevedo R, Fjeldheim AK, Bolstad K, Garcia L,et al.Preclinical immunogenicity study of trivalent meningococcal awx-omv vaccines for the african meningitis belt. Vaccine .2014;32(49):6631-6638. 